\title{
ERRATUM
}

\section{Communication of the role of natural variability in future North American climate}

Clara Deser, Reto Knutti, Susan Solomon and Adam S. Phillips

Nature Climate Change 2, 775-779 (2012); published online 26 October 2012; corrected after print 14 November 2012.

In the version of this Perspective originally published, the last label on the $x$ axis of Fig. 3b should have read '2050'. This error has now been corrected in the HTML and PDF versions. 